\title{
Uso de jogos matemáticos como proposta pedagógica num contexto de formação intercultural para professores indígenas $^{1}$
}

Keli Cristina Conti*

Nayara Katherine Duarte Pinto**

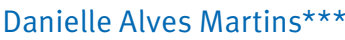

*(Universidade Federal de Minas Gerais - UFMG, Belo Horizonte, MG, Brasil)

**(Universidade Federal de Minas Gerais - UFMG, Belo Horizonte, MG, Brasil)

***(Secretaria de Educação de Minas Gerais - SEE/MG, Belo Horizonte, MG, Brasil)
Resumo: O presente trabalho foi desenvolvido com o objetivo de descrever a utilização do jogo Trinca-Espinhas e a criação do jogo Cabo de Guerra Numérico. Essas atividades foram desenvolvidas em um curso de formação de professores indígenas de uma universidade federal e fizeram parte de um projeto de pesquisa intitulado Contribuições do Laboratório de Ensino de Matemática para a formação inicial do professor que ensina matemática. As descrições dos jogos foram realizadas a partir de alguns momentos que analisamos serem produtivos durante as aulas na universidade e no território indígena. Nesse sentido, consideramos que essas atividades oportunizaram momentos de aprendizagem a partir de uma abordagem criativa, lúdica e divertida. Além disso, acreditamos que as reflexões produzidas aqui poderão contribuir para a formação de professores e futuros professores de matemática.

Palavras-chave: Educação matemática. Jogos. Uso do computador. Formação inicial de professores. Educação indígena. 
INTRODUÇÃO

Este trabalho faz parte de uma sequência de atividades desenvolvidas junto aos estudantes do curso de Formação Intercultural para Educadores Indígenas (Fiei), da Universidade Federal de Minas Gerais (UFMG), e integrou um projeto de pesquisa intitulado Contribuições do Laboratório de Ensino de Matemática para a formação inicial do professor que ensina matemática, que visou ampliar o Laboratório de Ensino de Matemática (LEM) na Faculdade de Educação da referida universidade. Além disso, esse projeto buscou analisar e interpretar práticas de formação e de atuação de futuros professores de forma a compreender e ressaltar a importância de um LEM para a formação inicial do professor que ensinará matemática e para o processo de ensino e aprendizagem dos estudantes. As atividades incluíram vivências em vários ambientes, como o Laboratório de Ensino de Matemática da universidade, o território indígena dos estudantes e o ambiente tecnológico².

Podemos dizer que o trabalho que aqui relataremos perpassou por essas questões, de análise e interpretação de práticas de formação e atuação dos futuros professores, destacando a importância do LEM, mas sem deixar para trás a interculturalidade, ou seja, considerando as produções dos próprios estudantes indígenas. Podemos dizer, também, que nossa prática foi uma busca por apresentar estratégias, mas sempre reconhecendo outras várias trazidas pelos professores indígenas.

Optamos, no desenvolvimento da pesquisa, pela abordagem qualitativa a fim de valorizar todos os dados (descrição detalhada de situações, contextos, pessoas, interações, comportamentos, falas de estudantes, atitudes, pensamentos, trechos de cadernos e relatórios) como importantes para assegurar o compromisso com a produção do conhecimento. Gostaríamos de salientar que a utilização dos nomes reais dos estudantes, em algumas passagens do texto, foi um pedido deles durante uma conversa, em sala, posterior ao desenvolvimento das atividades. Nessa conversa, apresentamos o texto e os participantes destacaram que a presença de seus nomes no artigo seria uma oportunidade de divulgar e valorizar suas etnias.

Passaremos a apresentar o curso de Formação Intercultural de Professores Indígenas. Posteriormente, introduziremos algumas breves notas sobre a

2 Uma versão preliminar da pesquisa foi publicada em: CÉSAR, Eloi Teixeira (Org.). Ciência em dia: jornadas de divulgação científica: a matemática está em tudo. São Paulo: Editora Livraria da Física, 2018. 
educação escolar indígena e o uso de jogos e outras tecnologias nas aulas de matemática, que serão reflexões importantes para detalharmos o contexto da primeira atividade.

\section{A FORMAÇÃO DE PROFESSORES INDÍGENAS}

A atividade foi desenvolvida na disciplina Prática de Ensino, do curso de Formação Intercultural de Educadores Indígenas (Fiei), na turma de habilitação em Matemática da UFMG. O Fiei é um curso que visa à formação de professores indígenas, com enfoque intercultural, para atuar nos ensinos fundamental e médio, buscando construir uma educação escolar indígena, intercultural, bilíngue, específica, diferenciada e prevista em lei. 0 curso possui quatro áreas de concentração (habilitações): Língua, Arte e Literatura (LAL), Ciências Sociais e Humanidades (CSH), Ciências da Vida e da Natureza (CVN) e Matemática (UFMG, 2011). O currículo do curso intercultural apresenta disciplinas relacionadas aos conhecimentos do mundo não indígena e também disciplinas e projetos de pesquisa relacionados aos conhecimentos tradicionais indígenas.

Mais especificamente, atuamos nesta última área de concentração, a Matemática, sendo que a primeira autora era, no período de desenvolvimento da atividade, a professora responsável por essa área de habilitação dentro do Fiei e pela disciplina em que foi desenvolvida a atividade; as outras duas autoras eram bolsistas do curso.

O curso está organizado em tempos/espaços diferenciados: são oito etapas chamadas de intensivas, desenvolvidas na universidade, e oito etapas chamadas de intermediárias, período de formação que ocorre em território indígena (meio sociocultural). No desenvolvimento da atividade, participaram 34 estudantes indígenas, das etnias Guarani, Maxakali, Pataxó, Pataxó Hã Hã Hãe e Xakriabá. Eles estavam no 5o período do curso e a maioria deles já eram professores em seus territórios indígenas.

As atividades foram desenvolvidas com os estudantes organizados em grupos ou individualmente. A primeira atividade que descreveremos foi desenvolvida na universidade, durante a etapa intensiva. Já a segunda foi desenvolvida no território indígena durante a etapa intermediária.

Feita uma breve descrição do contexto e dos estudantes, posteriormente apontaremos reflexões importantes, a nosso ver, sobre a educação escolar indígena para, após, apresentar breves notas a respeito da importância do uso de jogos nas aulas de matemática. 


\title{
A EDUCAÇÃO ESCOLAR INDÍGENA
}

Neste trabalho, concordamos com Brito (2012) sobre o fato de que a educação escolar indígena é distinta da educação indígena. Isso porque compreendemos a

\begin{abstract}
Educação Escolar Indígena como aquela que é totalmente vinculada à escola, regida, muitas das vezes, pelo modelo da escola tradicional (não indígena), podendo configurar-se como municipal, estadual ou de responsabilidade de ONGs e outras instituições. Já a Educação Indígena configura-se como a educação já existente em uma comunidade indígena e diz respeito a todos os ensinamentos referentes à tradição de um povo e/ou cultura (BRITO, 2012, p. 29).
\end{abstract}

Conforme aponta Silva (2001), a Constituição Brasileira deve garantir aos índios uma educação escolar indígena "respeitosa de suas línguas e culturas, de seus modos próprios de viver e pensar, de valorização de seus conhecimentos e dos processos próprios de sua produção e transmissão" (SILVA, 2001, p. 31). Para isso, é necessária uma educação que considere as especificidades dos povos indígenas, que busque contribuir para a valorização da identidade indígena e que tenha os saberes desses povos na centralidade de qualquer ação educacional. Isso porque, segundo Ferreira (2005),

\section{[...] é vital estar claro: os desejos indígenas são fundamentais, as línguas indígenas são fundamentais, os mitos de origem indígenas são fontes que dinamizam as suas culturas, seus universos constituem bases para a construção de uma educação escolar em um só tempo diferenciada e significativa (FERREIRA, 2005, p. 169).}

Nos últimos anos, o encontro entre indígenas e não indígenas tem se tornado cada vez mais intenso. Com isso, muitas vezes, laços de dependência são fortificados pela sociedade dominante. Em vista disso, evidencia-se a importância do fortalecimento da educação escolar indígena: “a construção de um espaço de aprendizagem e ensino que em um só tempo valorize os conhecimentos tradicionais da cultura indígena (na qual se efetiva a construção) e os conhecimentos provenientes do meio cultural dominante" (FERREIRA, 2005).

Nesse sentido, esses espaços educacionais requerem uma perspectiva intercultural de educação que leve em conta as necessidades indígenas e que lhes assegure o que é garantido por lei.

A sequência didática desenvolvida com os indígenas e relatada neste trabalho levou em conta todas essas questões, considerando o potencial dos jogos e do uso de computadores para uma formação intercultural. A seguir, apontaremos breves características importantes do uso dos jogos e dos computadores em relação ao ambiente educacional. 
Segundo Lopes (2009, p. 160), "há mais de um século que os jogos como recursos didáticos são propostos como alternativa metodológica a um ensino duro, estéril e desinteressante”. Quando pensamos no ensino de matemática de uma forma mais interessante, precisamos refletir sobre a inserção de discussões sobre jogos na formação inicial do professor. Assim, ao utilizarmos os jogos nesse contexto de formação, buscamos também refletir junto aos futuros professores e futuros professores de matemática sobre a utilização dos mesmos como possibilidade didático-pedagógica no trabalho com estudantes na escola básica.

Concordamos com Grando (2004) em relação ao fato de que ter os jogos como ferramenta de aprendizagem é essencial na instituição escolar para que os estudantes possam ter a oportunidade de deixar aflorar sua capacidade de elaborar estratégias, fazer previsões, perceber exceções e realizar a análise de possibilidades acerca da situação de jogo. Daí a importância dos jogos na formação de professores e, em especial, dos que ensinam matemática.

Os jogos também são ressaltados nos Parâmetros Curriculares Nacionais (PCN), desde os anos iniciais, como um caminho para se "fazer Matemática na sala de aula” (BRASIL, 1997, p. 42), destacando que:

Um aspecto relevante nos jogos é o desafio genuíno que eles provocam no aluno, que gera interesse e prazer. Por isso, é importante que os jogos façam parte da cultura escolar, cabendo ao professor analisar e avaliar a potencialidade educativa dos diferentes jogos e $o$ aspecto curricular que se deseja desenvolver (BRASIL, 1997, p. 42).

Em documento mais recente - a Base Nacional Comum Curricular (BNCC) -, também há menções ao uso de jogos, apontados como recurso didático que "precisam estar integrados a situações que propiciem a reflexão, contribuindo para a sistematização e a formalização dos conceitos matemáticos” (BRASIL, 2017, p. 254).

Nessa direção, outra ferramenta que tem se tornado importante no ambiente escolar é a tecnologia. "Nos últimos anos, tem-se observado o uso cada vez mais disseminado dos computadores e de outras tecnologias, que trazem uma grande mudança em todos os campos da atividade humana" (BRASIL, 2001, p. 09), tornando-se parte essencial do nosso cotidiano.

A possibilidade de se utilizar, separadamente ou em combinações, sons, 
imagens e animações permitiu novas maneiras de nos comunicarmos, contribuindo para a produção e disseminação de informações e conhecimentos. Assim, o avanço das tecnologias propiciou novas alternativas para diversos segmentos da sociedade.

No campo educacional, várias pesquisas revelam o importante papel das tecnologias no processo de ensino e aprendizagem (GONÇALVES, 2012; CARNEIRO; PASSOS, 2014). Para Bettega (2010, p. 18), a utilização de tecnologias “deve servir para enriquecer o ambiente educacional, propiciando a construção de conhecimento por meio de uma atuação ativa, crítica e criativa por parte de alunos e professores".

Nesse sentido, o uso de computadores em sala de aula passou a ser uma das possibilidades de se desenvolverem atividades investigativas, que contribuem para a aprendizagem dos estudantes. Além disso, segundo Fernandes (2004), o computador como tecnologia educacional favorece novas maneiras de acessar informações, possibilitando novas fontes de pesquisa em sala. Por meio do computador, professor e estudante podem explorar softwares educativos, o que pode ajudar em diferentes conteúdos disciplinares.

Cientes, então, do potencial das tecnologias e da importância dos jogos para a formação de professores e para o ensino, desenvolvemos uma sequência de atividades envolvendo o jogo Trinca-Espinhas. 0 contexto do desenvolvimento da atividade foi o Laboratório de Ensino de Matemática (LEM) na Faculdade de Educação da universidade, durante a etapa intensiva do curso Fiei. O jogo será descrito com mais detalhes a seguir.

Trinca-Espinhas

O jogo Trinca-Espinhas faz parte de um CD-ROM disponibilizado gratuitamente pelo Ministério de Educação de Portugal. No CD-ROM, chamado de Clic Mat (PORTUGAL, 2005), são disponibilizadas 32 atividades interativas destinadas a estudantes do $1^{0}$ ao 9 을 ano do ensino fundamental. O Trinca-Espinhas tem como objetivo, junto aos estudantes da escola básica, o trabalho com múltiplos e divisores de números naturais e números primos. No nosso caso, utilizamos na formação de professores que atuarão com estudantes do 6으 ao 9ํano, discutindo a metodologia para sua utilização em sala de aula.

Passaremos a descrever o jogo, a partir do que Grando (2004, p. 45) chama de "momentos do jogo", ou seja, a dinâmica que consideramos produtiva para a sala de aula. De acordo com a autora, são sete momentos: 1) familiarização com o material do jogo, 2) reconhecimento das regras, 3) jogar para garantir as 
regras, 4) intervenção pedagógica verbal, 5) registro do jogo, 6) intervenção escrita e 7) jogar com competência (GRANDO, 2004).

Inicialmente garantimos que os estudantes tivessem instalado o software ${ }^{3}$ previamente em seus computadores. O primeiro momento foi 0 de “Familiarização com o material do jogo" (GRANDO, 2004, p. 45) e se constituiu na localização do jogo entre os demais e o primeiro contato com sua interface (Figura 1). Nenhum dos estudantes conhecia o jogo.

Figura 1 - Interface do jogo Trinca-Espinhas

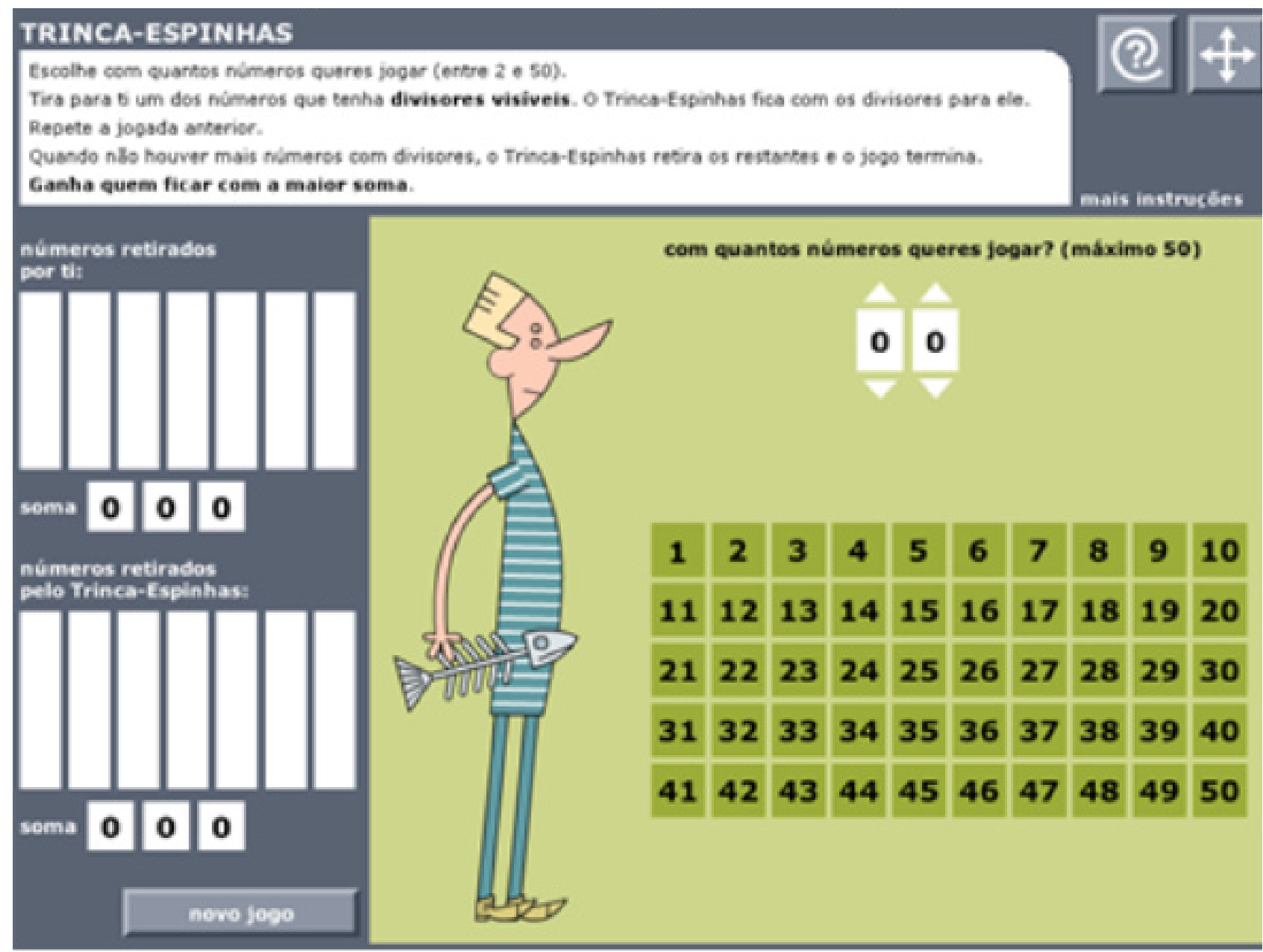

Fonte: Arquivo das autoras.

Logo depois, passamos para o momento de "reconhecimento das regras" (GRANDO, 2004, p. 51). Elas são visualizadas logo no topo da página e permanecem visíveis durante todo o tempo (Quadro 1). Foram lidas uma a uma, durante um diálogo com os estudantes.

Disponível em: 〈http://www.dge.mec.pt/clicmat-atividades-interativas-de-matematica〉.

Acesso em: 26 ago. 2016. 
Quadro 1 - Regras do jogo Trinca-Espinhas

Regras do jogo:

1. Escolhe o intervalo de números com que queres jogar.

2. Podes escolher qualquer número que tenha divisor na lista.

3. O Trinca-Espinhas fica com os divisores dos teus números.

4. Tu pontuas o total dos números que escolheste.

5. O Trinca-Espinhas pontua a soma dos divisores dos teus números e os que no fim restarem na lista.

Fonte: Portugal (2005).

Após a leitura das regras, foi simulada a primeira jogada, buscando realizar o que Grando (2004, p. 54) chama de “jogar para garantir as regras”, ou seja, garantir a apropriação das regras pelos estudantes. Para essa situação foram selecionados 20 números e a proposta foi coletiva, a partir da projeção do jogo no quadro por um equipamento multimídia. Ao se escolher o número 20 para iniciar a partida, ele fica registrado no primeiro placar como "números retirados por ti”, já apresentando a pontuação “20”. Já no segundo placar, intitulado "números retirados pelo Trinca-Espinhas", são apresentados os divisores de "20", que, de acordo com a regra, são do Trinca-Espinhas: 1, 2, 4, 5 e 10, o que totaliza a somatória de 22 pontos (Figura 2). Concluímos, então, que não foi uma boa jogada, pois o Trinca-Espinhas já inicia o jogo com uma vantagem de dois pontos. Na jogada seguinte, escolhemos mais um número e o Trinca-Espinhas ficou com seus divisores, e assim sucessivamente. 


\section{Figura 2 - Simulação de uma jogada}

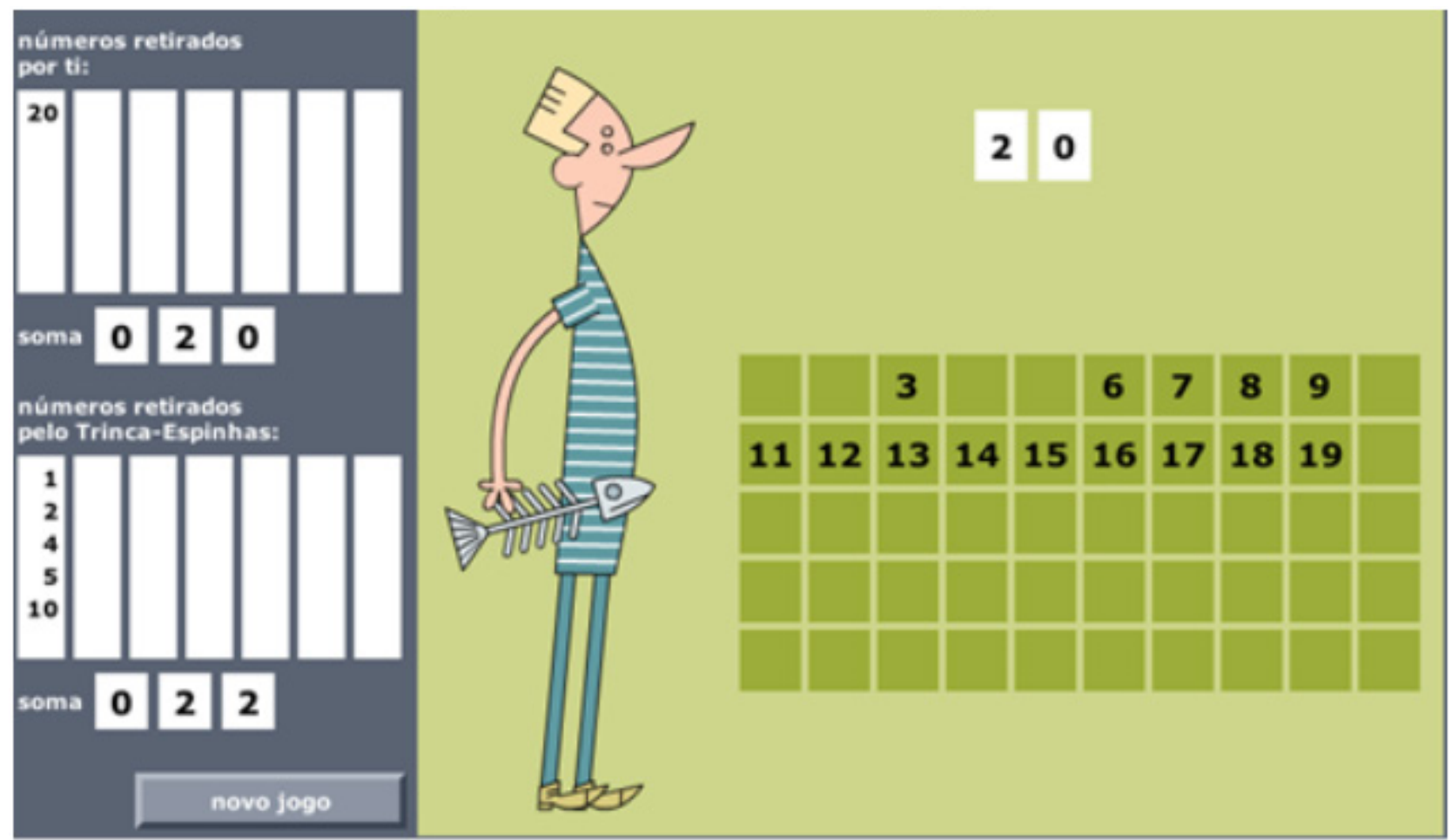

Fonte: Arquivo das autoras.

Ao longo da primeira partida, os estudantes foram indagados sobre qual número gostariam de retirar e observavam os números que ficavam com o Trinca-Espinhas. Ao terminarem, constataram que o Trinca-Espinhas foi 0 vencedor. Como Grando (2004) enfatiza, trata-se de um momento para "o jogar espontâneo", para garantir o entendimento das regras. Logo após a primeira partida, os estudantes começaram uma nova, alguns individualmente e outros em dupla.

As primeiras partidas foram ganhas pelo Trinca-Espinhas. Isso foi algo que incomodou e motivou os estudantes, pois eles queriam ganhar o jogo. Um dos estudantes conseguiu rapidamente uma estratégia para vencer o TrincaEspinhas: selecionou dois números para jogar. Como isso, ele retirou o número 2 e o Trinca-Espinhas retirou o número 1, totalizando dois pontos para ele e um ponto para o Trinca-Espinhas.

Motivados por essa estratégia, de selecionar uma quantidade reduzida de números para visualizar melhor as possibilidades, alguns estudantes ampliaram um pouco o que foi proposto pelo colega, jogando com cinco números, por exemplo, mas de forma a vencer o jogo.

Após os estudantes estarem familiarizados com o jogo e suas regras, optamos 
por lançar desafios verbalmente com o intuito de a turma desenvolver estratégias para vencer o Trinca-Espinhas, em situações cada vez mais complexas. Esse momento corresponde ao definido por Grando (2004, p. 55) como “intervenção pedagógica verbal”, em que buscamos, por meio dos desafios e das intervenções ao longo do jogo, estimular os estudantes a repensarem suas jogadas e as estratégias para atingir os desafios, como, por exemplo, nas situações transcritas de gravações de áudio de diálogos com os estudantes Diovania e Jessiá:

Professora: Você ganhou?

Diovania: Ganhei!

Professora: Como você fez para ganhar?

Diovania: Peguei primeiro o 5 e ele pegou o 1. Eu peguei o 4 e ele pegou o 2 e o 3, que não tinha divisor mais, ele pegou para ele.

Professora: Dobra a quantidade! Isso que você pensou vai funcionar?

Jessiá: Eu joguei com 13.

Professora: Qual foi a estratégia?

Jessiá: Fui de 13, tem menos divisores. Aí você consegue.

Professora: Por que o 13?

Jessiâ: Porque só divide por 1 .

Professora: Então 13 é um bom número?

Jessiá: É um bom número...

Professora: E se depois você jogasse com 26, daria certo a mesma estratégia?

Durante nossa intervenção verbal, vão ficando mais nítidos os objetivos do jogo quanto ao estudo dos múltiplos, divisores e números primos.

Nesse sentido, no primeiro desafio coletivo, os estudantes deveriam escolher jogar com 30 números e tinham que ganhar do Trinca-Espinhas. A Figura 3 mostra o modo inicial do primeiro desafio.

4 A estudante havia selecionado cinco números para jogar. 
Figura 3 - Primeiro desafio coletivo

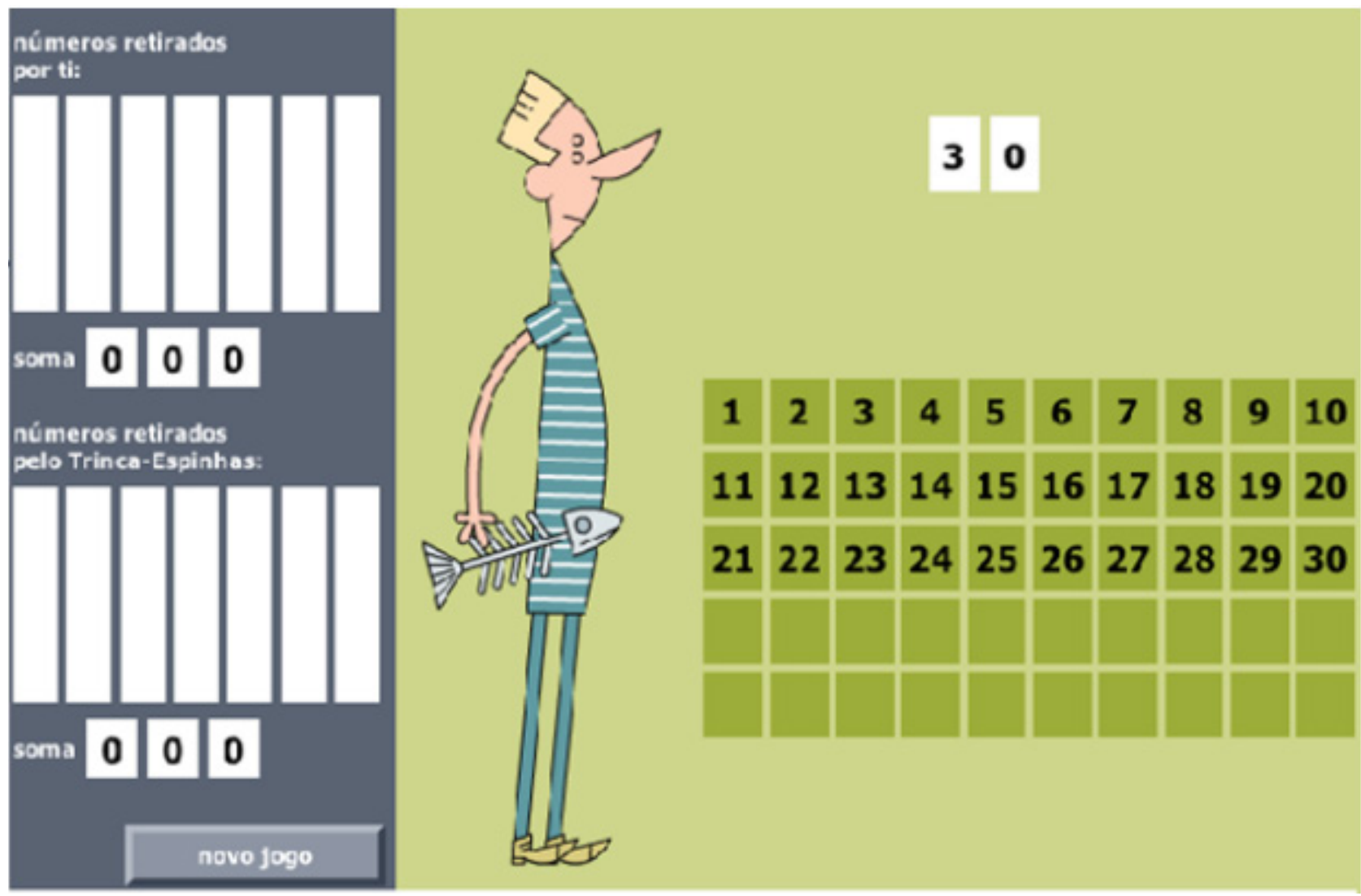

Fonte: Arquivo das autoras.

Por alguns minutos observamos que nenhum estudante tinha superado 0 desafio inicial. Diante disso, ficamos circulando entre as mesas questionando os estudantes sobre quais seriam as estratégias mais adequadas para se conquistar mais pontos. A situação transcrita do arquivo de áudio das intervenções verbais junto às estudantes Txahá e Karini exemplifica essa situação.

Professora: Você vai jogar com 30?

Txahá: Sim.

Professora: Ele fez 300 pontos! Por que você escolheu o 27 para começar, Txahá? Para ser o primeiro número que você tirou?

Txahá: Porque ele ia ganhar 1, mas aí ele ganhou o 1, o 3 e o 9.

Professora: Qual número ele ia ganhar só 1, se eu pegasse ainda 30 números para começar a jogar? E qual número que eu tiraria e ele pegaria só 1?

Txahá: Dos 30?

Professora: Dos 30. Seleciona 30... Escolhendo 27, você disse que ele tiraria só o 1, mas ele tirou o 1, o 3 e o 9. Qual o número dessa lista que 
é bom para eu tirar e ele pegaria só o 1?

Txahá: 07 também...

Karini: Não.

Professora: Mas é bom deixar os números maiores?

Txahá: Não.

Karini: Não.

Professora: Então seria bom eu tirar um número maior.

Karini: O 23. Que ele pega só 1 só.

Professora: E ele tirou só o 1? Você fez 23 e ele 1?

Karini: Sim.

Txahá: Verdade.

Professora: Teria um número maior que o 23 que é bom tirar?

Karini: 27.

Txahá: 29.

Professora: 0 29. Se você tirar o 29 ele vai tirar quanto?

Txahá: 1.

Professora: E nessa situação eu fiz mais pontos que 23. Quer tentar de novo? Reiniciar o jogo?

A partir dos diálogos, surge uma boa estratégia para se iniciar o jogo: iniciar escolhendo o maior número primo como a jogada que possibilita a maior pontuação inicial.

O primeiro estudante a ganhar foi o Manoel Aymoapte, com 296 pontos e o Trinca-Espinhas totalizando 169 pontos. A partir desse momento apareceram outros ganhadores, mas com menos pontos que o Manoel Aymoapte. Na continuidade dos desafios começou a suceder o momento denominado por Grando (2004, p. 59) como "registro do jogo", em que incentivamos os estudantes a anotarem no caderno as jogadas que eles realizaram para ganhar o jogo. Além disso, pedimos a eles que observassem quais jogadas poderiam ser alteradas para vencer o desafio com somatória maior que as obtidas anteriormente. 
Em um segundo momento, o primeiro desafio foi alterado: com os mesmos 30 números escolhidos, os estudantes deveriam obter 300 pontos (pontuação máxima possível com essa quantidade de números). Os estudantes, então, começaram a desenvolver a estratégia de fotografar com o celular todas as jogadas, discutindo depois os ajustes que poderiam contribuir para aumentar a pontuação.

Após muitos registros escritos, fotográficos e discussões, alguns estudantes conseguiram alcançar a pontuação máxima (Figura 4). Depois disso, optamos por realizar uma discussão coletiva a respeito das estratégias utilizadas e das variações encontradas entre as ordens dos números retirados para obtenção da pontuação máxima.

Figura 4 - Registro fotográfico da pontuação máxima do jogo com 30 números

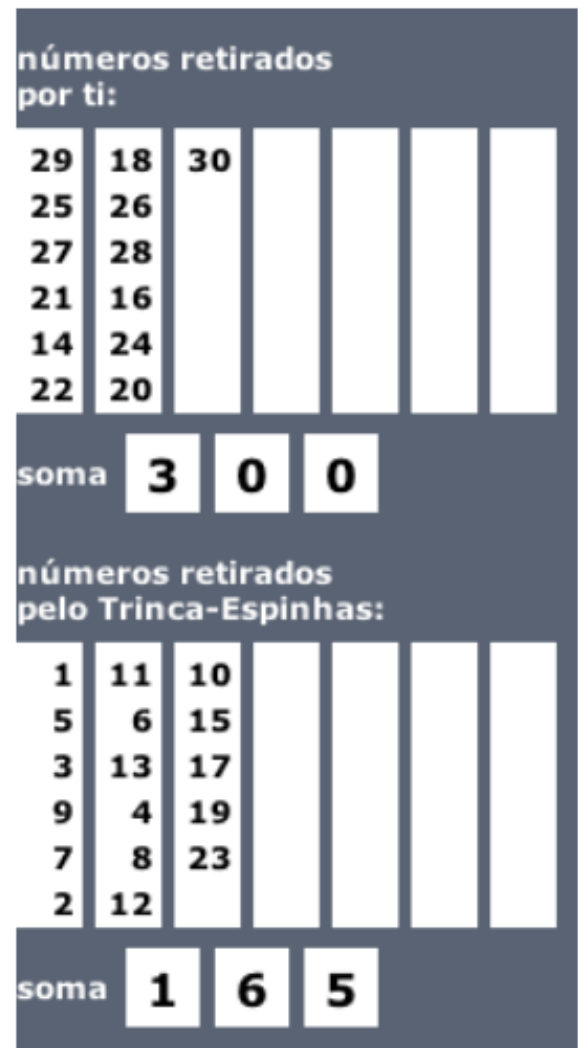

Fonte: Arquivo das autoras.

Quanto ao momento da “intervenção escrita” (GRANDO, 2004, p. 60), em que o trabalho é com problematizações de situações do jogo, optamos por pedir aos 
estudantes que, em grupos, elaborassem e resolvessem problemas a partir do Trinca-Espinhas. Durante a elaboração, percebemos que foi necessário, muitas vezes, voltar ao jogo e conferir as possibilidades. Foram recebidas 23 propostas. Algumas delas se assemelhavam mais a um exercício, algumas com pequenos equívocos que precisaram ser discutidos junto aos estudantes e que, nem por isso, foram ruins.

Optamos por selecionar pelo menos uma proposta de cada grupo de estudantes e propor como uma atividade a ser realizada em casa e, posteriormente, corrigida. Por exemplo:

Elaborado pelos estudantes Amagilda, Diovania e Sirê Mayõ: utilizando um tabuleiro com cinco números, qual jogada deverá ser feita para que o Trinca-Espinhas ganhe a partida?

Elaborado pelos estudantes Jonatan Txaywãtxuab'hy Ylwakkwãhy Pataxó e Jessiá: uma jogada com o Trinca-Espinhas, com 30 números, se eu escolher o número 10 para iniciar o jogo, o meu oponente vai tirar o 1, o 2 e o 5; e depois, se eu tirar o 18, ele vai obter 3, 6 e 9. Agora, juntando todos os valores dos números que eu escolhi, mais os números 24 e 28, quantos pontos eu terei? E meu oponente?.

Elaborado pelos estudantes Pollayne, Edmar Xakriabá e Neuza: em um tabuleiro com 25 números, no Trinca-Espinhas, qual seria o melhor número para se iniciar a jogada? Justifique sua resposta.

Elaborado pelos estudantes Kamarú, Alberto e Leandro: identifique na tabela dos números de 1 a 50, no Trinca-Espinhas, todos os números primos.

Elaborado pelos estudantes Gislaine, Ara Poty e Txahá: no Trinca- Espinhas, num tabuleiro com dez números, qual é a maior pontuação que pode ser obtida no jogo?

Durante a resolução dos problemas, muitos estudantes relataram que precisaram voltar ao jogo e que, nessa situação, já se lembravam das estratégias e jogavam com “mais competência” (último momento do jogo). Durante a correção das situações, de forma coletiva, não foram sentidas dificuldades na turma.

Nas avaliações da proposta foram recebidas boas indicações de que aprovaram o jogo e suas possibilidades, como nas avaliações escritas recebidas dos estudantes: 
Estudante Sirê Mayõ: O Trinca-Espinhas também é um jogo estratégico, começamos a jogar com números menores até entender o jogo. E depois que entendemos, tornou-se muito divertido.

Estudante Jonatan Txaywãtxuab’hy Ylwakkwãhy Pataxó: Foi um jogo muito bom, pois com ele pudemos ter a ideia de divisão apresentada de uma maneira divertida e dinâmica. Eu gostei muito desse jogo e pretendo entrar no software para ver e jogar outros jogos.

Estudante Haywã: Jogo muito bom, que desperta o raciocínio lógico da pessoa que está jogando. Gostei muito.

Estudante Pollayne: Amei esse jogo. No início estava perdendo todas as partidas para o computador. Depois comecei a avaliar as jogadas e comecei a ganhar, e ainda tivemos a oportunidade de elaborar questões relacionadas ao jogo.

Infelizmente também foi relatada uma limitação, por alguns estudantes: a falta de computadores nas escolas indígenas. Como no exposto pelos estudantes Alípio Xakriabá e Manoel Aymoapte:

Estudante Alípio Xakriabá: Gostei muito. Eu queria aplicar na sala com meus alunos, mas não tem computadores. Quando houver uma oportunidade eu vou aplicar porque é muito bom.

Estudante Manoel Aymoapte: Esse jogo é bom, mas para ser jogado é preciso computador. Isso dificultaria muito nas nossas escolas, nas aldeias, porque nem todas são equipadas

Nesse momento, também discutimos coletivamente possibilidades para a realização do jogo usando cartões de papel ou fichas. Nessa proposta, jogando com dois participantes, um deles retira um número e o seu oponente, seus divisores, somando as fichas ou cartões ao final. E, por isso, consideramos que os estudantes precisam ter um conhecimento mais consolidado de divisores, pois essa proposta exige maior atenção justamente na retirada dos divisores.

Depois de conhecermos um jogo escolar que faz uso do computador, fizeram parte do trabalho, já que são estudantes de curso intercultural, que busca trazer conhecimentos do mundo não indígena e os relacionados aos conhecimentos tradicionais, durante a etapa intermediária, o resgate e a apresentação ou criação de jogos desenvolvidos nos territórios indígenas de cada etnia. Os estudantes apresentaram alguns jogos resgatados de conversas com anciões das aldeias, alguns jogos de que os estudantes se lembravam de praticar quando eram crianças e alguns jogos escolares. Aqui escolhemos dar destaque ao jogo criado pelo estudante Kamarú da etnia Pataxó, que passaremos a descrever a seguir. 


\section{Cabo de Guerra}

A ideia inicial de Kamarú foi criar um jogo que levasse em conta aspectos relacionados à cultura indígena para trabalhar conteúdos e conceitos matemáticos no âmbito escolar. Nessa direção, era de interesse mostrar que é possível usar elementos relativos ao saber tradicional indígena, juntamente com o saber escolar, numa prática pedagógica, nesse caso, um jogo matemático. Para ele, este tipo de atividade poderia contribuir para que os alunos melhorassem seu desempenho na disciplina de maneira mais descontraída.

Dentre as diversas práticas culturais do povo Pataxó, o referido estudante escolheu uma das modalidades tradicionais dos Jogos dos Povos Indígenas: o Cabo de Guerra. Esse jogo, que também pode ser chamado de Cabo de Força, é um dos mais praticados pelos indígenas, em especial pelos Pataxós. Segundo Vinha (2004, p. 4), nos Jogos dos Povos Indígenas, em 2001, “o jogo cabo-de-guerra ocupou uma posição privilegiada: a condição de uma das provas mais esperadas, tanto para os indígenas quanto para o público".

A autora relatou também que o desenvolvimento do jogo deve ser feito a partir de

duas equipes posicionadas em colunas, frente a frente, segurando uma única corda grossa que se apoia na mão de todos os participantes das equipes. A prova consiste em cada equipe puxar a corda para seu lado, tentando deslocar um objeto que marca o ponto central da corda, até que a equipe contrária se renda pela força (VINHA, 2004, p. 4).

Com base na descrição do jogo Cabo de Guerra, que faz parte da cultura indígena, na próxima seção apresentaremos o jogo matemático criado por Kamarú.

O jogo Cabo de Guerra Numérico

Esta seção foi escrita a partir do relatório feito e entregue por Kamarú sobre o jogo Cabo de Guerra Numérico, criado por ele como forma de avaliação da disciplina Prática de Ensino. Em relação à construção do jogo, segundo Kamarú, a maior dificuldade foi estabelecer as suas regras. Nesse sentido, foram necessários diversos testes, de forma que o jogo foi sendo aprimorado. Segundo o estudante, ele realizava testes com sua irmã, Yamani, e o jogo passava por alterações nas regras. Dessa forma, o jogo foi sendo moldado até serem estabelecidas as regras permanentes. 
Para a implementação do jogo, na etapa intermediária do curso, realizada na aldeia de Boca da Mata, foi preciso confeccionar uma quantidade expressiva de materiais: tabuleiros, fichas e dados. Segundo Kamarú, foi necessária ajuda para produzir o material: “Minha irmã, a Yamani, e minha mãe, a Pariry Mayná, tiveram papel fundamental ao me ajudar a confeccionar mais fichas com números usados no jogo".

Além disso, segundo o estudante, o contato anterior com outros jogos foi importante para que ele elaborasse seu próprio jogo:

Se eu não tivesse conhecido os jogos como o Kalah e principalmente o Contig 60, apresentado no módulo [período intensivo] de estudo do Fiei - matemática - pela professora, praticamente não teria ideia de como relacionar um jogo matemático com alguma prática cultural. Por isso, o jogo criado, que recebeu o nome de Cabo de Guerra Numérico, faz relembrar alguns elementos presentes no jogo Contig 60, como fichas, dados, tabuleiro e sentenças numéricas (Kamarú em relatório produzido).

Nesse trecho do relato de Kamarú foram citados dois jogos, o Kalah e o Contig 60 , utilizados durante o período em que os alunos estavam em uma das etapas intensivas na universidade. Para obtenção de maiores informações sobre esses jogos, sugerimos consultar Brasil (2008) e Grando (2004).

Segundo Kamarú, o Cabo de Guerra Numérico é um jogo de estratégia que visa trabalhar os cálculos mentais a partir da sorte com os dados. Os cálculos envolvem as operações básicas e os números inteiros. Para confeccioná-lo são necessários os seguintes materiais: tabuleiro (Figura 5), 42 fichas (21 fichas de cada cor) e dois dados.

Figura 5 - Tabuleiro do jogo Cabo de Guerra Numérico

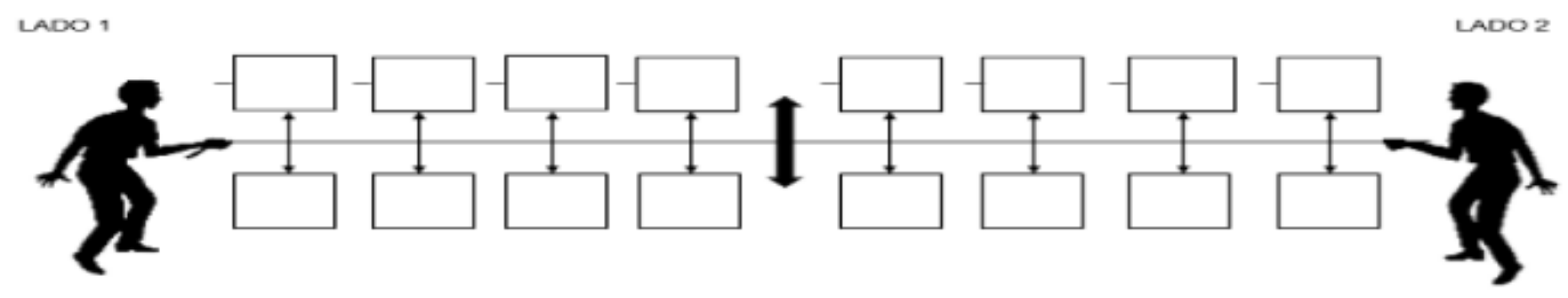

Fonte: Elaborado pelo estudante Kamarú.

O jogo deve ser realizado respeitando-se as seguintes regras:

Regra 1: O lado (1 ou 2) de jogada (ver Figura 5) e a cor da ficha (a ficha pode 
ser confeccionada com a cor de preferência de cada um) devem ser decididos antes de começar o jogo. Isso pode ser realizado a partir de vários critérios, como, por exemplo, no "par ou ímpar". A partir daí, cada jogador (ou dupla de jogadores) joga alternadamente. 0 primeiro jogador lança os dois dados e, pelos números indicados em suas faces superiores, deverá construir uma sentença numérica usando uma das quatro operações básicas (adição, subtração, multiplicação ou divisão) para obter um resultado com número inteiro positivo. Se, por exemplo, no primeiro dado lançado saísse o número 6 e, no segundo dado lançado, o número 2, poderíamos ter as seguintes expressões numéricas e seus respectivos resultados: $6+2=8,6-2=4$, 6 x $2=12,6: 2=3$.

Observação: Utilizando as quatro operações básicas e os dois dados, há 21 possibilidades de resultados, sendo 13 números pares, 0, 2, 4, 6, 8, 10, 12 , $16,18,20,24,30,36$ e oito ímpares, 1, 3, 5, 7, 9, 11, 15, 25. A imagem a seguir (Figura 6) mostra todas essas possibilidades: em verde estão os resultados pares e, em azul, os ímpares. Os números foram marcados apenas uma vez, por mais que tivessem resultados iguais. Logo, cada jogador receberá 21 fichas, considerando que será uma ficha para cada resultado possível.

Figura 6 - Possibilidades de resultados

\begin{tabular}{|c|c|c|c|c|c|c|}
\hline ADIC. & 1 & 2 & 3 & 4 & 5 & 6 \\
\hline 1 & 2 & 3 & 4 & 5 & 6 & 7 \\
\hline 2 & 3 & 4 & 5 & 6 & 7 & 8 \\
\hline 3 & 4 & 5 & 6 & 7 & 8 & 9 \\
\hline 4 & 5 & 6 & 7 & 8 & 9 & 10 \\
\hline 5 & 6 & 7 & 8 & 9 & 10 & 11 \\
\hline 6 & 7 & 8 & 9 & 10 & 11 & 12 \\
\hline
\end{tabular}

\begin{tabular}{|c|c|c|c|c|c|c|}
\hline MULTI & 1 & 2 & 3 & 4 & 5 & 6 \\
\hline 1 & 1 & 2 & 3 & 4 & 5 & 6 \\
\hline 2 & 2 & 4 & 6 & 8 & 10 & 12 \\
\hline 3 & 3 & 6 & 9 & 12 & 15 & 18 \\
\hline 4 & 4 & 8 & 12 & 16 & 20 & 24 \\
\hline 5 & 5 & 10 & 15 & 20 & 25 & 30 \\
\hline 6 & 6 & 12 & 18 & 24 & 30 & 36 \\
\hline
\end{tabular}

\begin{tabular}{|c|c|c|c|c|c|c|}
\hline SUBT. & 1 & 2 & 3 & 4 & 5 & 6 \\
\hline 1 & 0 & & & & & \\
\hline 2 & 1 & 0 & & & & \\
\hline 3 & 2 & 1 & 0 & & & \\
\hline 4 & 3 & 2 & 1 & 0 & & \\
\hline 5 & 4 & 3 & 2 & 1 & 0 & \\
\hline 6 & 5 & 4 & 3 & 2 & 1 & 0 \\
\hline
\end{tabular}

\begin{tabular}{|c|c|c|c|c|c|c|}
\hline DIVI. & 1 & 2 & 3 & 4 & 5 & 6 \\
\hline 1 & 1 & & & & & \\
\hline 2 & 2 & 1 & & & & \\
\hline 3 & 3 & & 1 & & & \\
\hline 4 & 4 & 2 & & 1 & & \\
\hline 5 & 5 & & & & 1 & \\
\hline 6 & 6 & 3 & 2 & & & 1 \\
\hline
\end{tabular}

Fonte: Elaborada pelas autoras.

Regra 2: 0 jogador, após construir a sentença numérica e resolvê-la, colocará a ficha que tenha o número do resultado da sentença no seu lado do jogo. Cada 
lado do jogo terá oito resultados, sendo que os quatro resultados colocados na parte superior ficarão negativos e os quatro resultados colocados na parte inferior continuarão positivos.

Regra 3: Se os resultados das sentenças forem números ímpares, terão valores dobrados se forem colocados na parte superior.

Regra 4: Se todas as fichas das possibilidades de combinação dos dois dados lançados numa jogada já tiverem sido utilizadas, deve-se jogar os dados novamente.

Regra 5: 0 jogo termina quando ambos os lados estiverem completos, tanto a parte inferior quanto a superior. Vence quem obtiver o número igual ou mais próximo a "0" na soma de todos os resultados de seu respectivo lado.

Durante o jogo

No período de desenvolvimento da atividade, junto aos estudantes do curso, pudemos notar que, na primeira vez que jogamos, as regras ainda pareciam um pouco confusas. Após nos familiarizarmos com elas, ficou mais fácil e divertido.

Na situação descrita abaixo, um estudante que chamaremos de Jogador 1 (cor verde/lado esquerdo do tabuleiro) joga contra outro estudante, que chamaremos de Jogador 2 (cor laranja/lado direito do tabuleiro) (Figura 7).

Nessa situação de jogo, o Jogador 1 já tem 5 pontos, pontuação formada pelos resultados obtidos, do lado negativo 0 e do lado positivo 2 e 3 . 0 Jogador 2 tem 1 , formado pelos resultados obtidos do lado negativo -3 (que, de acordo com as regras do jogo, vale -6 , por ser ímpar e estar do lado negativo) e o 7. Ainda na jogada, o Jogador 2, ao tirar nos dados 2 e 6, opta por fazer uma subtração $(6-4)$ e seleciona a ficha 4 para ser colocada no tabuleiro. 0 Jogador 2 pode optar por colocar sua ficha na parte superior e ela passará a valer -4 , ficando com um total de pontos de -3 , ou poderá colocá-la na parte inferior, em que valerá 4; nesse caso, ficará com 5 de saldo. Trata-se de um importante momento para o jogador avaliar qual é a posição mais vantajosa, pois vence o jogo, depois de todas as peças colocadas, quem obtiver soma zero ou mais próxima de zero. 


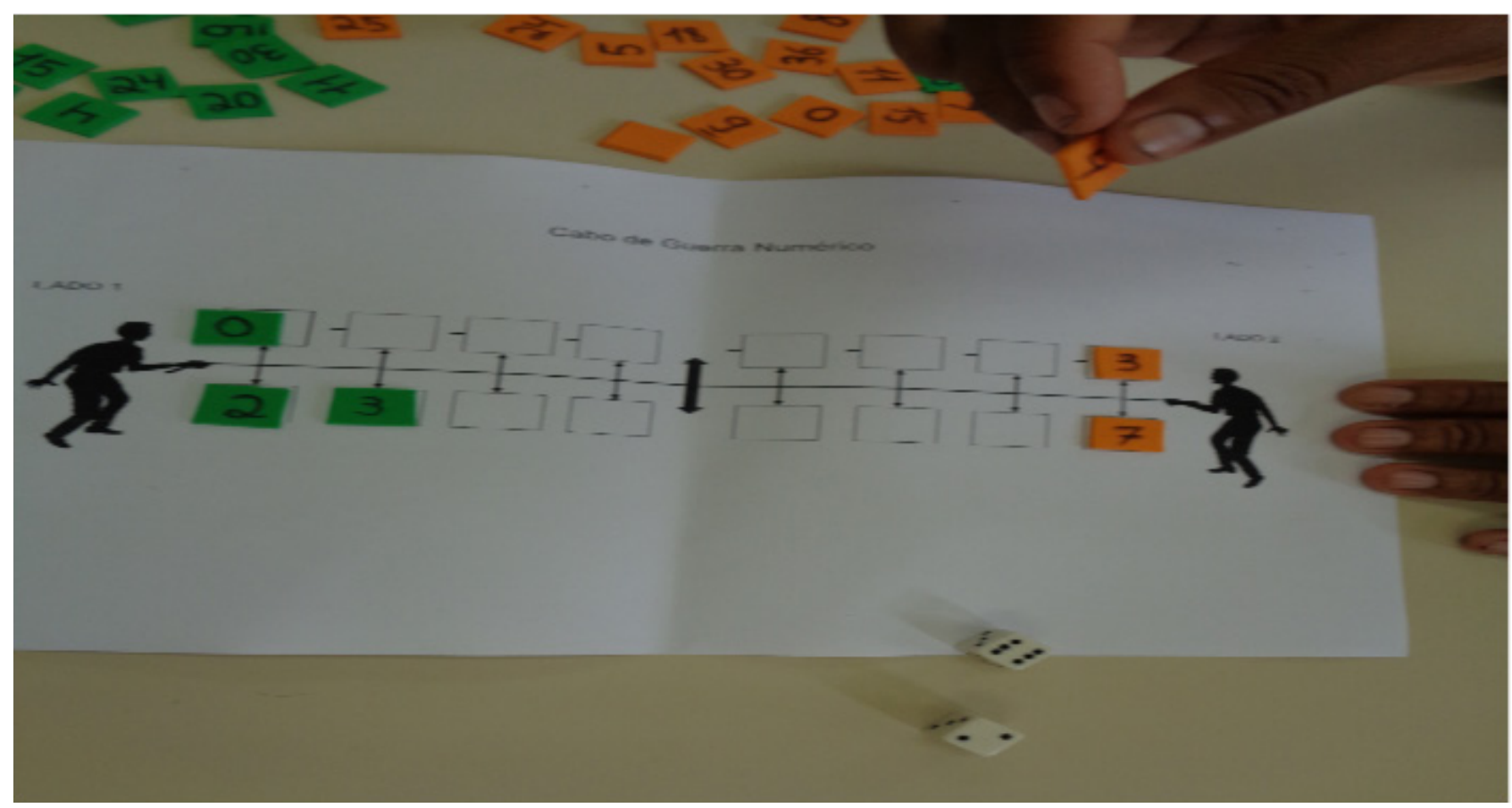

Fonte: Arquivo das autoras.

Os estudantes dependem da sorte, ao jogar os dados, e de estratégia, a fim de escolher a melhor operação a ser utilizada e a posição da ficha a ser colocada no tabuleiro (superior/negativo ou inferior/positivo). Durante a escolha da melhor estratégia, os estudantes precisam operar com os números inteiros. Mais uma partida sendo disputada pode ser encontrada na Figura 8.

Figura 8 - Partida sendo disputada

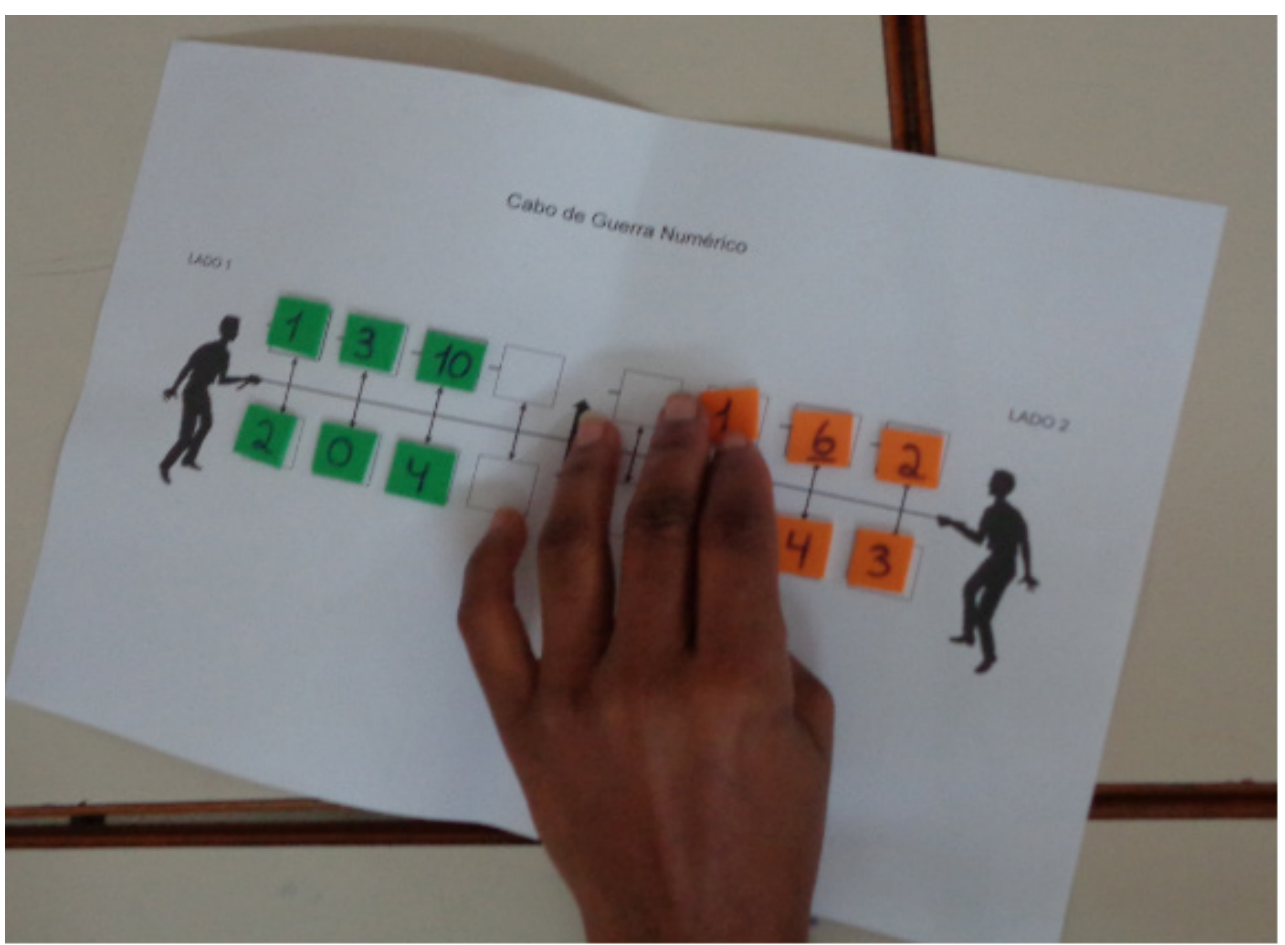

Fonte: Arquivo das autoras. 
Para além do jogo Cabo de Guerra Numérico

O jogo criado por Kamarú teve inspiração em um jogo matemático, no entanto, ele conseguiu relacionar esse mesmo jogo a uma prática indígena. Consideramos que o exercício do estudante em pensar sobre o ensino de matemática por meio da associação desse conteúdo a um jogo indígena resultou em um aprendizado valioso para ele.

Gostaríamos de ressaltar também que, embora Kamarú tenha criado o jogo com base no que vivenciou na etapa intensiva e na cultura Pataxó, acreditamos que o tabuleiro possa incorporar mais elementos da cultura indígena que eventualmente diferenciem os jogadores ou elementos presentes na disputa do Cabo de Guerra, como o cocar ou a vestimenta típica (contextualização).

Por parte dos estudantes do curso que puderam conhecer o jogo e disputar partidas com os colegas, obtivemos uma boa avaliação.

O intermódulo foi muito produtivo, mesmo com tanto calor. Pudemos adquirir mais conhecimentos com os jogos e os momentos partilhados com as pessoas e lideranças da comunidade (estudante Txayara).

Pudemos contar com aprendizado dentro da sala de aula e aulas fora da sala. $O$ exemplo disso foram os jogos, onde pudemos reunir a participação de todos e é isso que fortalece nosso curso intercultural, porque passamos a valorizar a nós mesmos e as vivências que encontramos no que diz respeito a cada aldeia que visitamos e compartilhamos o que temos em nossas aldeias (estudante Txaywã txuab).

Que tal nos aprofundarmos mais nos jogos da cultura Pataxó? Além de aprendermos vários outros jogos matemáticos indígenas que ainda não conhecemos (estudante Edilande).

Por meio das declarações dos participantes, pudemos notar indícios da importância do curso intercultural e a valorização dos conhecimentos indígenas dos participantes.

\section{ALGUMAS CONSIDERAÇÕES}

Consideramos que a proposta atingiu os objetivos almejados ao oportunizar momentos de discussão com os futuros professores de matemática acerca de tornar a aprendizagem escolar mais lúdica e divertida por meio de jogos e, ao mesmo tempo, por meio de uma abordagem metodológica que possibilita a valorização dos saberes e das práticas presentes na cultura dos participantes, destacando mais uma vez o caráter intercultural da proposta. Ademais, as atividades narradas oportunizaram o uso de tecnologia, a vivência dos 
momentos do jogo (GRANDO, 2004) - indo além do "jogar" -, bem como a exploração de conteúdos matemáticos envolvendo as quatro operações básicas, múltiplos, divisores e números primos, tendo como contexto a formação de professores.

Para além do que foi desenvolvido junto aos estudantes, consideramos que a proposta de escrita deste texto também proporcionou reflexões acerca do trabalho que desenvolvemos com eles, contribuindo com nosso crescimento pessoal. Nesse sentido, esperamos contribuir com a formação de outros professores e futuros professores que ensinam matemática em diversos contextos, e para que estudantes indígenas do ensino fundamental possam se aproximar mais da própria cultura por meio do ensino de matemática a partir dos jogos. 


\section{Using Mathematical Games as a Pedagogical Proposal in a Context of Intercultural Education for Indigenous Teachers}

Abstracts: The goal of the present paper is to describe the use of the TrincaEspinhas game, as well as the creation of the 'Numerical Tug of War'. These activities were developed in a training course for indigenous teachers at a federal university and were part of a research project titled Contribuições do Laboratório de Ensino de Matemática para a formação inicial do professor que ensina matemática [Contributions of the Mathematics Teaching Laboratory to Initial Education for Teachers who Teach Mathematics]. Our description of the games focused on points that we considered productive during the classes at the university and in an indigenous territory. Therefore, we consider that these activities provided participants with learning opportunities through a creative, playful and fun approach. In addition, we believe that the reflections presented here may contribute to the education of teachers and future mathematics teachers of mathematics.

Keywords: Mathematics education. Games. Computer use. Initial teacher education. Indigenous education. 


\section{Uso de juegos matemáticos como propuesta pedagógica en un contexto de formación intercultural para profesores indígenas}

Resumen: El presente trabajo se desarrolló con el objetivo de describir la utilización del juego «Trinca-Espinhas» y la creación del juego «Cabo de Guerra Numérico». Estas actividades se desarrollaron en un curso de formación de profesores indígenas de una universidad federal de Brasil y fueron parte de un proyecto de investigación titulado Contribuições do Laboratório de Ensino de Matemática para a formação inicial do professor que ensina matemática [Contribuciones del Laboratorio de Enseñanza de Matemáticas para la formación inicial del profesor que enseña matemáticas]. Las descripciones de los juegos se realizaron a partir de algunos momentos que, según nuestro análisis, fueron productivos durante las clases en la universidad y en el territorio indígena. En este sentido, consideramos que tales actividades propiciaron momentos de aprendizaje a partir de un enfoque creativo, lúdico y divertido. Además, creemos que las reflexiones aquí realizadas podrán contribuir a la formación de profesores y futuros profesores de matemáticas.

Palabras clave: Educación matemática. Juegos. Uso de la computadora. Formación inicial de profesores. Educación indígena. 


\section{REFERÊNCIAS}

BetTegA, Maria Helena Silva. Educação continuada na era digital. 2 ed. São Paulo: Cortez, 2010.

BRASIL. Conselho Nacional de Educação. Parecer CNE/CP 009/2001 de 8 de maio de 2001. Dispõe sobre as Diretrizes para a Formação de Professores da Educação Básica, em nível superior, cursos de licenciatura, de graduação plena. Diário Oficial da União, Brasília, 18 abr. 2001. Disponível em: «http:// mec.gov.br/> Acesso em: 16 ago. 2016.

. Ministério da Educação. Base Nacional Comum Curricular (BNCC). Educação é a Base. Brasília, MEC/Consed/Undime, 2017.

- Ministério da Educação e do Desporto. Secretaria de Educação Fundamental. Parâmetros Curriculares Nacionais: matemática. Brasília: MEC/ SEF, 1997.

Pró-letramento: programa de formação continuada de professores dos anos/séries iniciais do ensino fundamental: matemática. Secretaria da Educação Básica. Brasília: MEC/SEF, 2008.

BRITO, Ruana Priscila da Silva. Apropriação das práticas de numeramento em um contexto de formação de educadores indígenas. 2012. 268 f. Dissertação (Mestrado em Educação)-Faculdade de Educação da Universidade Federal de Minas Gerais, Belo Horizonte, 2012.

CARNEIRO, Reginaldo Fernando; PASSOS, Carmen Lúcia Brancaglion. A utilização das tecnologias da informação e comunicação nas aulas de matemática: limites e possibilidades. Revista Eletrônica de Educação, v. 8, n. 2, p. 101-119, 2014.

FERNANDES, Natal Lânia Roque. Professores e computadores: navegar é preciso. Porto Alegre: Mediação, 2004.

FERREIRA, Rogério. Educação escolar indígena e etnomatemática: a pluralidade de um encontro na tragédia pós-moderna. 2005. 269 f. Tese (Doutorado em Educação) - Faculdade de Educação da Universidade de São Paulo, São Paulo, 2005.

GONÇALVES, Ávila de Cásio. Computadores na sala de aula: o projeto UCA - um computador por aluno - na escola classe 102 do Recanto das Emas Distrito Federal. Revista Brasileira de Aprendizagem Aberta e a Distância, v. 
11, 2012. Disponível em: 〈http://www.abed.org.br/revistacientifica/Revista_ PDF_Doc/2012/artigo_06_v112012.pdf〉. Acesso em: 6 nov. 2016.

GRANDO, Regina Célia. O jogo e a matemática no contexto da sala de aula. São Paulo: Paulus, 2004.

LOPES, Antônio José; GIMENEZ, Joaquim. Metodologia para o ensino da aritmética: competência numérica no cotidiano. São Paulo: FTD, 2009.

PORTUGAL. Ministério da Educação de Portugal, Direcção Geral de Inovação e Desenvolvimento Curricular. Clic Mat: atividades interativas de matemática. Lisboa, 2005.

SILVA, Aracy Lopes da. Uma “Antropologia da Educação” no Brasil? Reflexões a partir da escolarização indígena. In: SILVA, Aracy Lopes da; FERREIRA, Mariana Kawall Leal. Antropologia, história e educação: a questão indígena e a escola. 2. ed. São Paulo: Global, 2001.

UNIVERSIDADE FEDERAL DE MINAS GERAIS. Projeto Pedagógico do Curso de Formação Intercultural de Professores. Belo Horizonte, 2011.

VINHA, Marina. Tradição recentemente inventada - Terras indígenas e jogo “Cabo-de-Guerra”. In: ENCONTRO REGIONAL DE HISTÓRIA - O LUGAR DA HISTÓRIA, 17., 2004, Campinas. Anais... Campinas: Anpuh/SPUnicamp, 2004. CD-ROM.

\section{SOBRE AS AUTORAS}

Keli Cristina Conti é doutora em Educação pela Universidade Estadual de Campinas (Unicamp). Atua como pesquisadora e professora do Departamento de Metodologia e Técnicas de Ensino (DMTE) da Faculdade de Educação (FaE) da Universidade Federal de Minas Gerais (UFMG).

E-mail: keli.conti@gmail.com

Nayara Katherine Duarte Pinto é mestranda do Programa de Pós-graduação em Educação e Docência na linha de pesquisa Educação Matemática. Graduada em Matemática pela Universidade Federal de Minas Gerais (2016). Atua como bolsista do curso de Licenciatura em Educação do Campo da Faculdade de Educação da Universidade Federal de Minas Gerais.

E-mail: nayarakatherine@hotmail.com 
Danielle Alves Martins é licenciada em Matemática pela Universidade Federal de Minas Gerais (2012); especialista em Mídias na Educação pela Universidade Federal de Ouro Preto (2015); mestra em Educação pelo programa de Pósgraduação em Educação da Universidade Federal de Minas Gerais, na linha de pesquisa Educação Matemática. Atualmente é professora da Secretaria de Educação de Minas Gerais.

E-mail: daniellemartins125@hotmail.com.

Recebido em: abril de 2018

Aceito em: maio de 2018 